\title{
Does interferon- $\gamma$ improve pulmonary function in idiopathic pulmonary fibrosis?
}

\author{
A. Prasse*, K-M. Müller\#, C. Kurz", H. Hamm , J.C. Virchow Jr ${ }^{\S}$
}

Does interferon- $\gamma$ improve pulmonary function in idiopathic pulmonary fibrosis? $A$. Prasse, K-M.Müller, C. Kurz, H. Hamm, J.C. Virchow Jr. C)ERS Journals Ltd 2003. ABSTRACT: Idiopathic pulmonary fibrosis (IPF) is a disease with progressive and devastating deterioration of lung function and a fatal prognosis, despite aggressive therapeutic attempts, which, in the majority of cases are futile.

Recently, a preliminary study of long-term treatment with interferon (IFN)- $\gamma_{1 b}$ and low-dose prednisolone in patients with IPF suggested that IFN- $\gamma_{1 b}$ treatment may improve lung function parameters of patients with IPF. Ever since, specialists in respiratory medicine who treat patients with IPF, are called by patients demanding treatment with IFN- $\gamma_{1 b}$. Therefore, the authors here present another prospective investigation of IFN- $\gamma_{1 b}$ in five patients with IPF.

According to the previously published design, patients received $200 \mu \mathrm{g}$ IFN- $\gamma_{1 \mathrm{~b}}$ subcutaneously three-times per week and $10 \mathrm{mg}$ prednisolone orally for 12 months. Two patients stopped IFN- $\gamma_{1 b}$ treatment after 4 months due to side-effects and further lung function deterioration and one patient died 3 months after commencement of therapy. In total, pulmonary function improved in only one patient during IFN- $\gamma_{1 b}$ treatment, while four patients deteriorated.

To conclude, this small series of idiopathic pulmonary fibrosis cases treated with interferon- $\gamma_{1 b}$ and corticosteroids does not support previous data that this treatment improves pulmonary function or alters the natural course of idiopathic pulmonary fibrosis. Furthermore, in the authors' experience, side-effects of interferon- $\gamma_{1 b}$ treatment can significantly reduce patients' quality of life.

Eur Respir J 2003; 22: 906-911.
*Dept of Pneumology, and "Dept of Radiology, University Clinic, Freiburg, ${ }^{\#}$ Dept of Pathology, Berufsgenossenschaftliche Kliniken, Ruhr-Universität, Bochum, ${ }^{+}$Nordseeklinik Westerland, Sylt, and ${ }^{\S}$ Dept of Pneumology, University Medical Clinic, Rostock, Germany.

Correspondence: A. Prasse, Abteilung für Pneumologie, Medizinische Klinik, Universitätsklinikum Freiburg, Kilianstrasse 5, D-79106 Freiburg, Germany.

Fax: 497612703704

E-mail: prasse@med1.ukl.uni-freiburg.de

Keywords: Idiopathic pulmonary fibrosis interferon- $\gamma$ treatment pulmonary function therapy

usual interstitial pneumonia

Received: October 62002

Accepted after revision: July 282003
Idiopathic pulmonary fibrosis (IPF) is a devastating disease with progressive deterioration of lung function and a fatal prognosis, despite aggressive therapeutic attempts. Studies using the definition of IPF according to the renewed classification by KATZENSTEIN and MYERS [1] indicated that irrespective of treatment, the median survival of patients with IPF is 3-5 yrs after the onset of symptoms [2, 3]. No pharmacological therapy has been proven to alter or reverse the pathological changes of IPF [4]. Recently, a preliminary study of long-term treatment with interferon (IFN)- $\gamma_{1 b}$ and low-dose prednisolone in these patients, suggested that subcutaneous IFN- $\gamma$ treatment not only prevented further pulmonary function deterioration, but also led to a slight improvement of lung function parameters in IPF [5]. A reanalysis of this study on a case-by-case basis by RAGHU et al. [6] using the criteria of the American Thoracic Society (ATS)/European Respiratory Society (ERS)/American College of Chest Physicians (ACCP) [4] concluded that this study was limited by a low number of patients and heterogeneity in the patient cohort. Furthermore, the expert panel emphasised that the results needed confirmation by a phase-III clinical trial to determine the potential efficacy of IFN- $\gamma_{1 b}$ in the treatment of IPF.

The rationale to use recombinant IFN- $\gamma_{1 b}$ in the treatment of IPF is supported by in vitro data and animal studies. The production of collagen by fibroblasts is blocked by IFN- $\gamma$ [7]. In an animal model of bleomycin-induced pulmonary fibrosis,

For editorial comments see page 872. recombinant IFN- $\gamma$ ameliorated the resulting pulmonary fibrosis [8]. Furthermore, several studies suggested that in pulmonary fibrosis there is a shift towards a T-helper (Th) cell type-2 immune response [9]. Therefore, the Th1 cytokine IFN- $\gamma$ may be able to rebalance the shifted Th1/Th2 response [10].

Although the preliminary nature of their results was emphasised by the authors [5] and further studies were requested (that are now ongoing), this study generated enormous demand for IFN- $\gamma$ treatment in affected patients. Since the publication of the study, specialists for respiratory medicine attending IPF patients in Europe, and presumably also in North America, have been approached by patients demanding treatment with IFN- $\gamma_{1 b}$ despite its enormous costs. Based on this background, the authors have treated five patients with IPF with IFN- $\gamma_{1 \mathrm{~b}}$. The authors acknowledge that this study has similar limitations to those previously reported [5]. The present data with IFN- $\gamma_{1 b}$ in the treatment of IPF, which is based on a similar number of patients as previously published, will aid in such therapeutic decisions.

\section{Methods}

Patients were enrolled for treatment after giving written informed consent. The study was approved by the local ethics committee. Recombinant IFN- $\gamma_{1 b}$ was kindly provided by Boehringer Ingelheim, Biberach an der Riss, Germany. Every patient received IFN- $\gamma_{1 \mathrm{~b}}$ subcutaneously in a maintenance 
dose of $200 \mu \mathrm{g}$ three-times per week. The initial dose was $50 \mu \mathrm{g}$, which was increased by $50 \mu \mathrm{g}$ per injection until the maintenance dose was reached. During therapy, patients were allowed to take paracetamol as needed to treat side-effects of IFN- $\gamma_{1 b}$, namely flu-like symptoms. In addition, every patient was maintained on low-dose prednisolone (10 mg once daily), which all patients had received prior to entry into the study without any noticeable clinical improvement or improvement in pulmonary function parameters.

\section{Pulmonary function}

Repeated pulmonary function tests were performed in a body plethysmograph (Jäger, Würzburg, Germany). Bloodgas analyses were performed with arterialised capillary blood from the earlobe at rest and during a steady-state bicycle exercise at a level of $25,50,75$ or 100 Watts depending on the clinical status of the patient. The carbon monoxide transfer factor $(D \mathrm{~L}, \mathrm{CO})$ was measured by a single-breath method, using a gas mixture of $0.2 \%$ carbon monoxide and $8 \%$ helium and was corrected for haemoglobin levels.

Patients' follow-up visits were arranged at least every 3 months with complete lung function testing at each visit. The response to IFN- $\gamma_{1 b}$ was determined according to the published ATS/ERS/ACCP criteria [4]. Total lung capacity (TLC) improvement was defined as an increase of $\geqslant 10 \%$ of the predicted per cent value or an absolute increase of $\geqslant 200 \mathrm{~mL}$. A response was regarded as stable when the change in TLC was not $>9 \%$ or $<200 \mathrm{~mL}$, and worsening was defined as a decrease in TLC of $\geqslant 10 \%$ or a decrease of $\geqslant 200 \mathrm{~mL}$. An improvement in arterial oxygen tension $\left(\mathrm{Pa}, \mathrm{O}_{2}\right)$ was defined as an increase of $\geqslant 0.53 \mathrm{kPa}(4 \mathrm{mmHg})$ from baseline, a stable response was recognised as a change of $<0.53 \mathrm{kPa}(4 \mathrm{mmHg})$, and a worsening in $\mathrm{Pa}, \mathrm{O}_{2}$ was defined as a decrease of $\geqslant 0.53 \mathrm{kPa}(4 \mathrm{mmHg})$ from baseline. An increase of $\geqslant 15 \%$ predicted of $D \mathrm{~L}, \mathrm{CO}$ was defined as an improvement. Worsening $D \mathrm{~L}, \mathrm{CO}$ was defined as a decrease of $\geqslant 15 \%$ pred.

\section{Histopathological analysis}

An initial histopathological analysis of open lung biopsies was performed at the local pathology institutes, where each biopsy was performed. For final reanalysis, specimens were sent to an expert pulmonary pathologist. The histopathological diagnosis of IPF was based on typical microscopic findings in the absence of infection, granuloma, vasculitis or malignancy. Tissue sections were examined according to the recently published criteria by KATZENSTEIN and MYERS [1], which were adopted by the ATS/ERS/ACCP [4]. These are defined as a nonuniform histological pattern with zones of fibroblast foci, normal lung architecture, alveolitis and interstitial fibrosis.

\section{High-resolution computed tomography: thorax}

High-resolution computed tomography (HRCT) scans were available for each patient. An expert group of two specialists for respiratory medicine and one radiologist reviewed all scans. The diagnosis of IPF on HRCT was made according to the published criteria by the ATS/ERS/ ACCP [4]. These are defined as patchy, predominately peripheral, subpleural bibasilar reticular abnormalities and ground-glass opacities, usually limited in extent. In areas of more severe involvement and advanced disease, traction bronchiectasis and bronchioloectasis and/or subpleural honeycombing was described. The ATS/ERS/ACCP state that the accuracy of a confident computed tomography diagnosis of IPF made on HRCT by a trained observer appears to be $\sim 90 \%$, according to data from JоHKOH et al. [11].

\section{Statistics}

Due to the limited patient number, results are reported by descriptive statistics only. To compare the patient cohort described by ZIESCHE et al. [5] with the present patient cohort, an unpaired t-test was performed.

\section{Results}

The study was started in 1997 , and the last patient was included in 2000. Five patients were enrolled in the study. Results are presented as mean \pm SD. Age was $57.8 \pm 7.6$ yrs and all patients were currently nonsmoking males. Three patients were significant exsmokers. Further patient characteristics are described in table 1 . Four of the five patients showed a usual interstitial pneumonia (UIP) pattern on histopathological examination of surgical lung biopsies (high confidence level), while one patient (patient 4) was classified as probable UIP. In this patient the tissue specimen showed only diffuse honeycombing and extensive interstitial fibrosis. Clinical and radiological data of this patient, however, also suggested IPF. In every patient, case history, clinical examination and laboratory analyses did not reveal any pathological results typical for rheumatic disease.

\section{High-resolution computed tomography scans}

Each patient showed predominantly bibasilar, subpleural honeycombing and more or less pronounced ground-glass opacification. The computed tomography scans of each patient were compatible with a UIP pattern according to the ATS criteria [4].

\section{Duration of therapy}

Two patients completed 12 months of treatment with IFN$\gamma_{1 b}$. Two patients terminated further therapy after 4 months because of side-effects (severe flu-like symptoms following IFN- $\gamma_{1 b}$ injection), in addition to further deterioration of pulmonary function. One patient died after 3.5 months of therapy with IFN- $\gamma_{1 b}$. At autopsy, the cause of death was attributed to acute right heart failure due to end-stage pulmonary fibrosis. Patient 3 decided to continue treatment after the study was finished.

\section{Pulmonary function}

TLC $\%$ pred before entry into the study was $57.2 \pm 9.1 \%$. At entry into the study, only one patient (patient 5) had a TLC that was $<50 \%$ pred. However, the baseline TLC $\%$ pred of the patient cohort was significantly lower (unpaired t-test, $\mathrm{p}=0.038$ ) than in the study by ZIESCHE et al. [5] (nine patients, TLC $70 \pm 10 \%$ ). After 12 months, mean TLC $\%$ pred decreased in three of four patients and one patient died (patient 5). Individual values are depicted in figure 1. In addition, there was a deterioration of mean $\mathrm{Pa}, \mathrm{O}_{2}$ at rest in three patients, one of which died (fig. 1). The individual 


\begin{tabular}{|c|c|c|c|c|c|}
\hline & \multicolumn{5}{|c|}{ Patient } \\
\hline & 1 & 2 & 3 & 4 & 5 \\
\hline Age yrs & 49 & 54 & 68 & 63 & 55 \\
\hline Origin & White & White & White & White & White \\
\hline Sex & Male & Male & Male & Male & Male \\
\hline Nationality & German & German & German & Assyrian & German \\
\hline First diagnosis & 1996 & 1992 & 1996 & April 1999 & 1997 \\
\hline Previous therapy & $\begin{array}{l}\text { Prednisolone since } \\
\text { 1996, warfarin } \\
\text { since } 1992\end{array}$ & $\begin{array}{l}\text { Prednisolone since } \\
\text { 1997, azathioprine } \\
\text { 1997- February } \\
1998\end{array}$ & $\begin{array}{l}\text { Prednisolone since } 1997, \\
\text { cyclophosphamide } \\
\text { 1997-1998 }\end{array}$ & $\begin{array}{l}\text { Prednisolone since } \\
\quad 1999\end{array}$ & $\begin{array}{l}\text { Prednisolone since } \\
\quad 1997\end{array}$ \\
\hline Concomitant disease & $\begin{array}{l}\text { Portal vein } \\
\text { thrombosis due } \\
\text { to protein C } \\
\text { and AT III } \\
\text { deficiency }\end{array}$ & Goiter & $\begin{array}{c}\text { Myocardial infarction } \\
\text { 1992, DVT } 1988\end{array}$ & $\begin{array}{l}1997 \text { transurethral } \\
\text { resection of } \\
\text { prostate gland }\end{array}$ & None \\
\hline Smoking status & $\begin{array}{l}20 \text { pack-yrs until } \\
1985\end{array}$ & $\begin{array}{l}50 \text { pack-yrs until } \\
1986\end{array}$ & 50 pack-yrs until 1992 & Never smoked & Never smoked \\
\hline Profession & Businessman & Heating technician & College teacher & Army officer & Lawyer \\
\hline $\begin{array}{l}\text { Treatment date with } \\
\text { IFN- } \gamma_{1 b}\end{array}$ & $\begin{array}{c}\text { September } 1997- \\
\text { January } 1998\end{array}$ & $\begin{array}{l}\text { May 1998- } \\
\text { September } 1998\end{array}$ & $\begin{array}{l}\text { May 1998-May } \\
1999\end{array}$ & $\begin{array}{l}\text { January } 2000- \\
\text { January } 2001\end{array}$ & $\begin{array}{l}\text { March 2000-June } \\
2000\end{array}$ \\
\hline Special remarks & $\begin{array}{l}\text { Sister died of } \\
\text { probable } \\
\text { IPF. Was listed } \\
\text { for LTx and } \\
\text { received a graft } \\
\text { lung in } 2000\end{array}$ & $\begin{array}{l}\text { Was listed for LTx } \\
\text { and received graft } \\
\text { lung May } 1999\end{array}$ & & Lost for follow-up & $\begin{array}{l}\text { Was listed for LTx. } \\
\text { Died after } 3 \\
\text { months of therapy } \\
\text { with IFN- } \gamma \text {; } \\
\text { autopsy findings } \\
\text { and clinical data } \\
\text { suggest right } \\
\text { heart failure }\end{array}$ \\
\hline TLC at study entry L & 5.4 & 4.2 & 4.0 & 3.3 & 4.0 \\
\hline TLC at end of study L & 4.1 & 4.1 & 4.6 & 2.9 & 3.8 \\
\hline IVC at study entry L & 3.9 & 2.4 & 2.7 & 1.7 & 2.7 \\
\hline IVC at end of study L & 2.8 & 2.4 & 2.8 & 1.6 & 2.5 \\
\hline FEV1 at study entry L & 3.2 & 2.1 & 2.1 & 1.6 & 1.7 \\
\hline
\end{tabular}

AT: antithrombin; DVT: deep vein thrombosis; IFN: interferon; IPF: idiopathic pulmonary fibrosis; TLC: total lung capacity; IVC: inspiratory vital capacity; FEV1: forced expiratory volume in one second; LTx: lung transplant.

courses of the TLCs are shown in figure 2. Patient 4 was lost to follow-up with pulmonary function tests, while patient 3 continued treatment after the end of this 1-yr study.

Mean $\mathrm{Pa}, \mathrm{O}_{2}$ at rest before entry into the study was $8.91 \pm 1.34 \mathrm{kPa}(67.0 \pm 10.1 \mathrm{mmHg})$, and on maximal exertion was $7.25 \pm 1.57 \mathrm{kPa}(54.5 \pm 11.8 \mathrm{mmHg}) . P \mathrm{aa}, \mathrm{O}_{2}$ at rest maintained stable in two patients and decreased in three patients by $>0.53 \mathrm{kPa}(4 \mathrm{mmHg})$. Furthermore, there was a decrease in the $\mathrm{Pa}, \mathrm{O}_{2}$ measured during maximally tolerated exertion in three of four patients by $>0.53 \mathrm{kPa}(4 \mathrm{mmHg})$. Based on
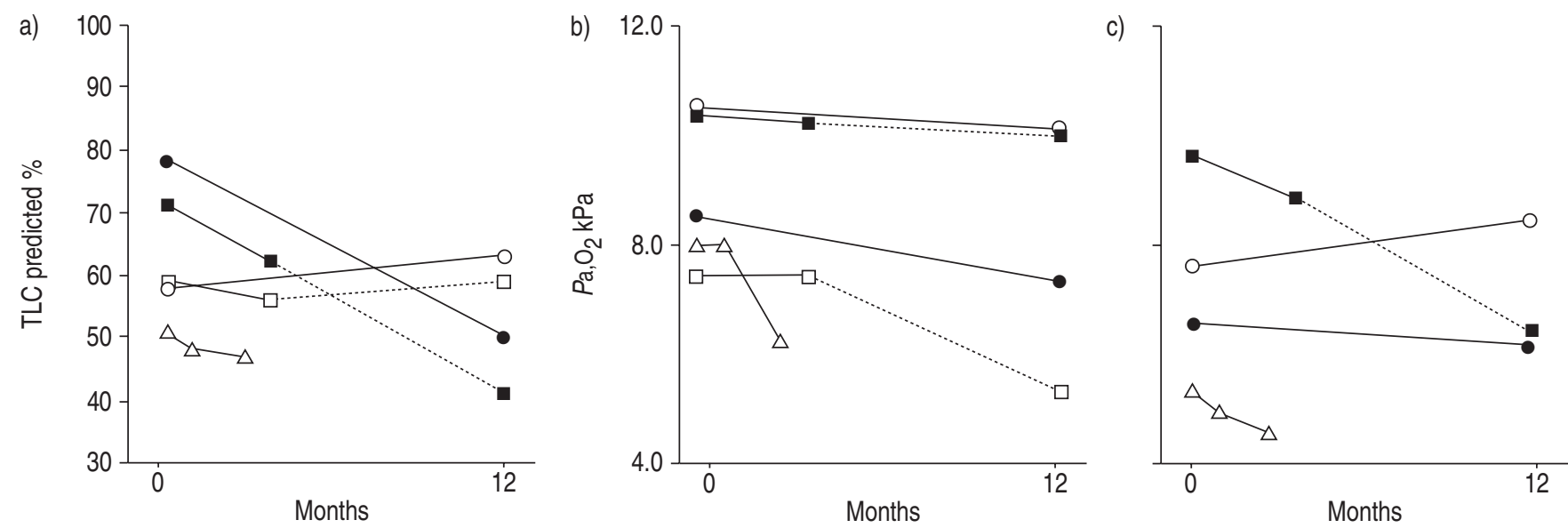

Fig. 1. - Total lung capacity (TLC) and arterial oxygen tension $\left(P_{\mathrm{a}, \mathrm{O}_{2}}\right)$ before and after 12 months of treatment with interferon (IFN)- $\gamma_{1 \mathrm{~b}}$ and prednisolone. a) Course of TLC per cent predicted. b) $\mathrm{Pa}_{\mathrm{a}} \mathrm{O}_{2}$ at rest. c) $\mathrm{Pa}, \mathrm{O}_{2}$ on maximal exertion. Two patients (patient 1 and 2) declined further IFN- $\gamma_{1 \mathrm{~b}}$ therapy after 4 months of treatment. These patients received prednisolone for a further 8 months (dotted line). Patient 5 died 3.5 months after starting IFN- $\gamma_{1 \mathrm{~b}}$ therapy. Patient 2 was excluded from bicycle training because of low $P_{\mathrm{a}, \mathrm{O}_{2}}$ at rest. $\mathbf{\square}$ : patient 1; $\square$ : patient 2; $\bigcirc$ : patient 3 ; $\bullet$ : patient $4 ; \triangle$ : patient 5 . 

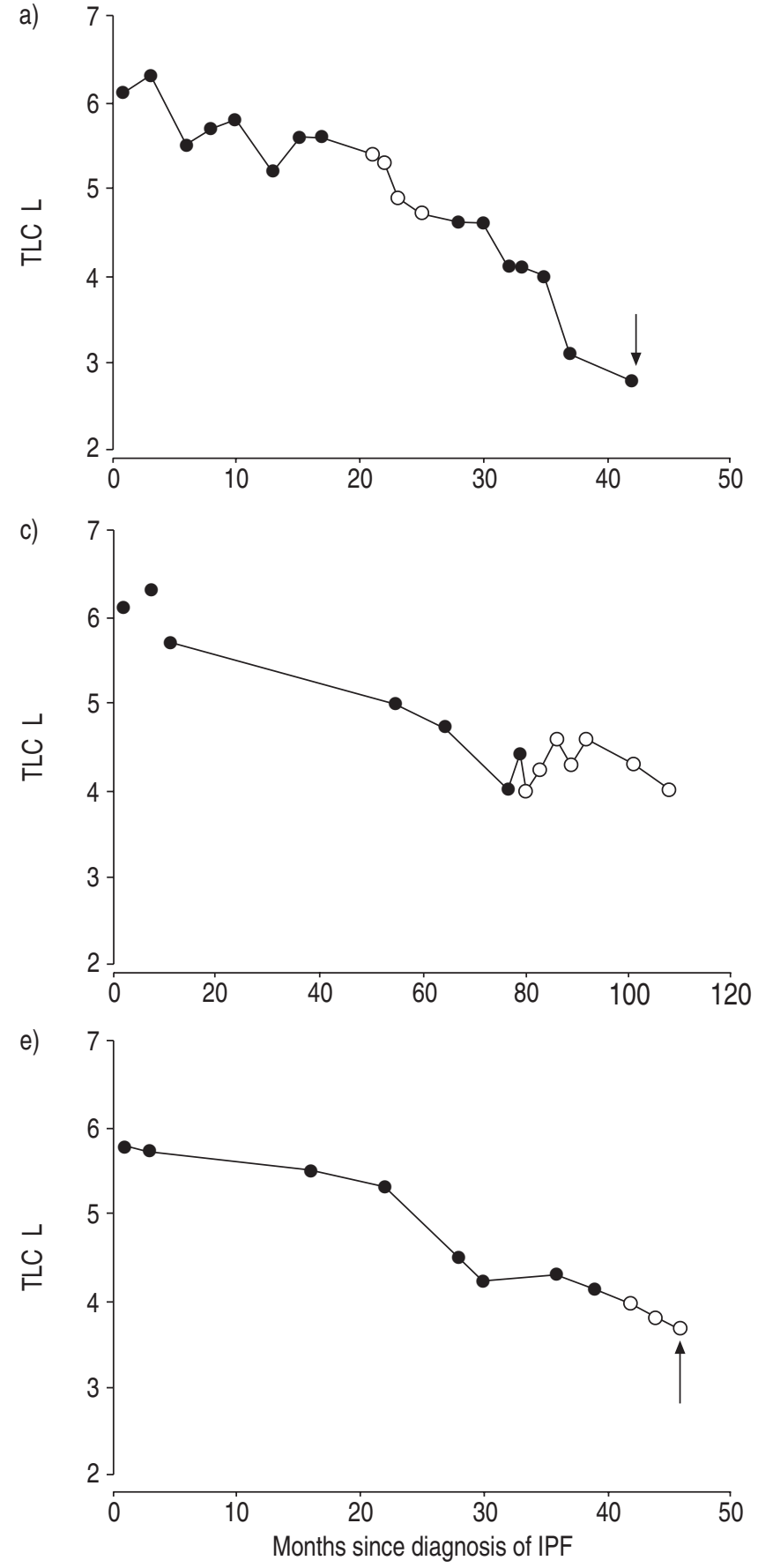

clinical findings in one patient it was decided to withhold exercise testing because of low baseline oxygen levels at rest and a considerable decrease in transcutaneously monitored oxygen saturation while speaking and slow walking. Individual values are depicted in figure 1 . Single-breath $D \mathrm{~L}, \mathrm{CO} \%$ pred decreased in one patient (patient 1) by $>15 \%$; while no patient improved, three patients remained stable (decrease by $<15 \%$ ). Individual values are shown in figure 3 .

\section{Discussion}

Based on an uncontrolled study in a small number of patients who were supposed to suffer from UIP and who were reported to improve with treatment of IFN- $\gamma_{1 b}$ and low-dose b)

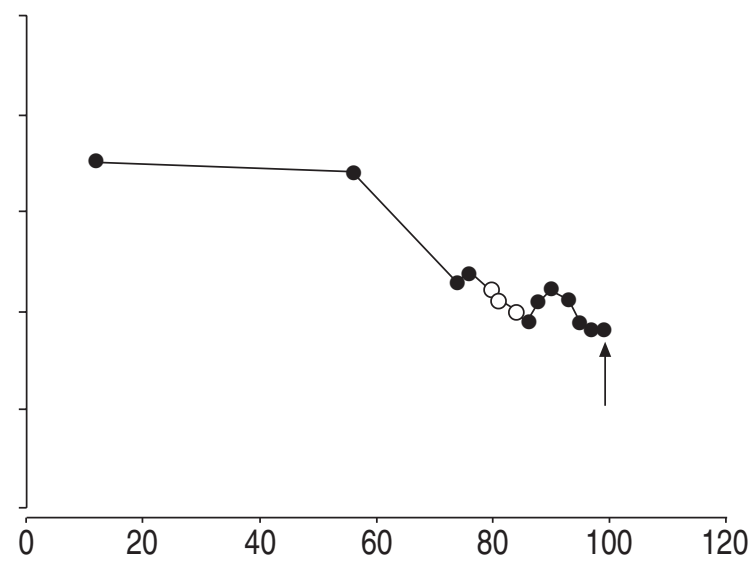

d)

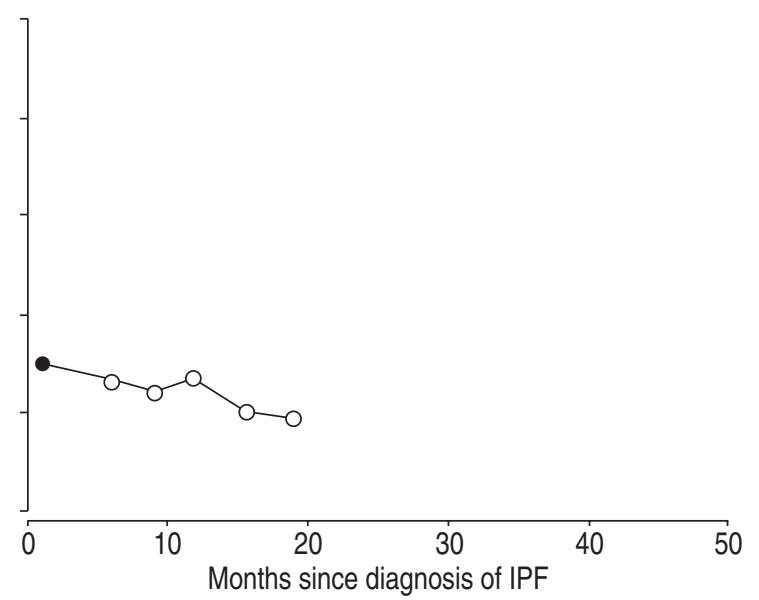

Fig. 2.-Course of total lung capacity (TLC) of each patient. a) Course of TLC in patient 1; immediately after starting interferon (IFN)- $\gamma_{1 \mathrm{~b}}$ treatment pulmonary function deteriorated. Therefore, treatment was terminated. The patient received a lung graft (arrow). b) Course of TLC in patient 2. The patient received a lung graft (arrow). c) Course of TLC in patient 3. The patient continued IFN$\gamma_{1 \mathrm{~b}}$ treatment after the study was finished. d) Course of TLC in patient 4 . The patient lost follow-up after the study was finished. e) Course of TLC in patient 5. The patient died after 3.5 months of therapy with IFN- $\gamma_{1 b}$ (arrow). At autopsy the cause of death was attributed to acute right heart failure due to end-stage pulmonary fibrosis. IPF: idiopathic pulmonary fibrosis. $\bigcirc$ : treatment with IFN$\gamma_{1 b} ;$ : no treatment.

prednisolone, a similar prospective investigation was performed. Criteria for the diagnosis of IPF in this series were a typical clinical presentation, pulmonary HRCT scans with a typical pattern, pulmonary function parameters and pathological evaluation of an open lung biopsy specimen. Thus, the diagnosis of IPF was established in the patient population with a high level of confidence. In contrast, however, to the results recently published [5], the authors' observations are less encouraging. During the study period, pulmonary function deteriorated in four of the five patients with IPF. One patient died 3 months after commencement of therapy. In fact, one patient, who had initially presented with only a moderate decline in pulmonary function over time, experienced a very rapid deterioration in TLC shortly after introduction of IFN- $\gamma_{1 b}$ therapy. In addition, this patient developed peripheral blood eosinophilia (7\%), which resolved 


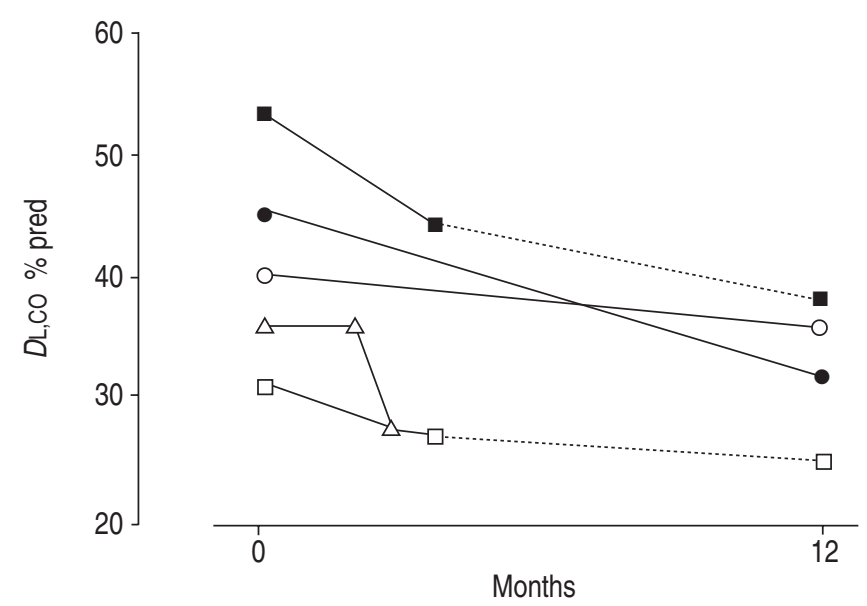

Fig. 3. - Single breath carbon monoxide transfer factor $(D \mathrm{~L}, \mathrm{CO})$ per cent predicted corrected for haemoglobin, before and after 12 months of treatment with interferon (IFN)- $\gamma_{1 b}$ and prednisolone. In two patients (patients 1 and 2), IFN- $\gamma_{1 b}$ therapy was stopped after 4 months of treatment. These patients received prednisolone for a further 8 months (dotted line). Patient 5 died 3.5 months after starting therapy. $\mathbf{\square}$ : patient $1 ; \square$ : patient 2; $\bigcirc$ : patient 3 ; $\bullet$ : patient 4; $\triangle$ : patient 5 .

after discontinuation of therapy. Improvement in pulmonary function after 12 months of therapy with IFN- $\gamma_{1 b}$ was observed in only one patient. This patient's TLC increased by $600 \mathrm{~mL}$ and the $\mathrm{Pa}, \mathrm{O}_{2}$ increased by $0.67 \mathrm{kPa}(5 \mathrm{mmHg})$ on maximal exertion. In this patient, $\mathrm{Pa}, \mathrm{O}_{2}$ at rest decreased by $0.40 \mathrm{kPa}(3 \mathrm{mmHg}$; a nonsignificant change according to ATS/ERS/ACCP criteria) and DL,CO \% pred decreased by $7 \%$ (also a nonsignificant change according to ATS/ERS/ACCP criteria). Although this patient decided to continue treatment after the end of the 1-yr study period, their pulmonary function deteriorated during the follow-up.

Clinical and radiological data were compatible with the diagnosis of IPF in all five patients investigated. In addition, the authors were able to get surgical lung biopsies in all patients. To increase the level of confidence with this diagnosis, all histological specimens were further evaluated by an independent pulmonary pathologist, who confirmed a UIP pattern in four patients and labelled one patient's biopsy tissue as compatible with end-stage pulmonary fibrosis, with extensive honeycombing from the obtained wedge resections. In connection with the HRCT scan of the thorax and clinical data, this patient was labelled as having probable UIP.

In a retrospective analysis of the study by ZIESCHE et al. [5], RAGHU et al. [6] determined that only four patients in this study had definite IPF in the group treated with IFN- $\gamma_{1 b}$. Five patients in the control group were considered to suffer from IPF, while two patients in the IFN- $\gamma_{1 b}$ treatment group and one patient in the control group did definitely not suffer from IPF. In the prednisolone-only control group from this study [5], seven patients were stable and one deteriorated. Interestingly, although based on a similar number of patients with IPF, it is surprising that in the identically designed present study four of five patients deteriorated despite IFN- $\gamma_{1 b}$ treatment. These differences may be based on patient selection. In the present study, baseline TLC \% pred was significantly lower $(\mathrm{p}=0.038)$ than in the other study [5]. However, there was no statistically significant difference in the mean $\mathrm{Pa}, \mathrm{O}_{2}$ at rest and on maximal exertion between the previous report [5] and the current patient cohort ( $\mathrm{p}=0.7$ and $\mathrm{p}=1.0$, respectively). It is therefore not entirely clear whether patients in the other cohort had predominantly earlier stages of the disease, as suggested by their better overall pulmonary function, whereas patients in the present study may have suffered from more advanced or more rapidly progressing IPF. Unfortunately, individual patient data concerning onset and progress of the disease to allow a formal comparison are not given in the previous report [5].

Since reliable data on the pre-study course of the individual patients are lacking and since only patients with an apparently relatively mild disease were included, the patient population investigated by ZIESCHE et al. [5] is most likely a highly unrepresentative population. In this context it is striking that even patients who were treated with placebo, progressed extraordinarily slowly. Unfortunately, it is a common clinical experience that patients with IPF tend to present late in the course of their disease. Thus, on the basis of the data available it seems premature to conclude that IFN- $\gamma_{1 b}$ treatment may be appropriate for patients with early stages of IPF. Two further reports $[12,13]$ regarding IFN- $\gamma_{1 b}$ treatment in IPF patients were published at the ACCP 2001 Congress. Both reports document the authors own experiences in uncontrolled, open studies. KALRA et al. [12] could not observe any improvement in 17 patients. In contrast, RAGHU et al. [13] observed a stabilisation upon IFN- $\gamma_{1 b}$ treatment in some patients with advanced IPF who had demonstrated previous deterioration despite prednisone and azathioprine therapy. Both reports are limited by inhomogenous duration of therapy, and open lung biopsy was not performed in all patients.

Another point of interest, which is in contrast to the report by ZIESCHE et al. [5], is the fact that the present authors observed considerable side-effects with subcutaneously administered IFN- $\gamma_{1 b}$. Although an identical dose of IFN- $\gamma_{1 b}$ was used, as in the protocol by ZIESCHE et al. [5], two of the present patients declined further therapy after 4 months because of intolerable side-effects, despite having actively sought this particular treatment in the face of a disabling and fatal disease. Both patients complained about severe flu-like symptoms following injections of IFN- $\gamma_{1 b}$. The peripheral blood eosinophilia that developed in one patient during treatment resolved after discontinuation of therapy. Peripheral blood eosinophilia is a common side-effect of interleukin-2 therapy, but it has not been reported with IFN$\gamma_{1 b}$. Recently, RAANANI and BEN-BASSAT [14] reported several immune-mediated complications during IFN therapy in haematological patients. Especially in patients with autoimmune disease, such as systemic lupus erythematodes, IFN$\gamma_{1 b}$ therapy may cause exacerbations including respiratory insufficiency $[15,16]$. Therefore, at present, underlying autoimmune disease should be carefully excluded in patients with pulmonary fibrosis before starting IFN- $\gamma_{1 b}$ treatment. One of the current patients had a history of myocardial infarction. In this patient, an ST depression without any change in cardiac enzyme levels and no clinical symptoms was observed. After 12 months of therapy, IFN- $\gamma_{1 b}$ was discontinued and these electrocardiogram abnormalities resolved. FRIESS et al. [17] described minor ventricular tachycardias in patients treated with IFN- $\gamma_{1 b}$. In the present study, coronary angiography in the patient showed no major stenosis, suggesting a submyocardial ischaemia. It is noteworthy that ZIESCHE et al. [5] reported that the side-effects (fever, chills, muscle pain) subsided within the first 9-12 weeks, a finding that the present authors cannot confirm.

IFN- $\gamma$ treatment has been previously investigated in progressive systemic sclerosis, a disease associated with pulmonary fibrosis [18], which can also show a UIP pattern. Although preliminary data [19] suggested some, however, nonsignificant benefit of IFN- $\gamma$ treatment in patients with pulmonary fibrosis, other studies failed to show any effects of IFN- $\gamma$ in patients with systemic sclerosis [20-22]. Overall, there was only a moderate (nonsignificant) effect on skin sclerosis and no significant change in pulmonary function [23]. However, 
these studies were limited by the fact that histopathological analysis of pulmonary fibrosis was lacking [19-22] and the dosage of IFN- $\gamma$ treatment was lower. All studies reported side-effects of IFN- $\gamma$ treatment in up to $65 \%$ of the study population and the mean drop-out rate resulting from sideeffects was $28 \%$ [23].

Based on the present authors' experience, they cannot recommend the use of interferon- $\gamma_{1 b}$ in idiopathic pulmonary fibrosis patients. Side-effects of interferon- $\gamma_{1 b}$ treatment significantly reduce the patients' quality of life with no convincing improvement in health status and pulmonary function. Especially in patients with advanced disease, those of older age and comorbidity, these side-effects have to be considered. Moreover, based on a similar treatment design with an identical protocol, the current authors could not reproduce the results of ZIESCHE et al. [5]. Although they cannot exclude that interferon- $\gamma_{1 b}$ treatment may be able to stabilise disease in patients presenting with an early stage of idiopathic pulmonary fibrosis, the effects are, in the authors' interpretation (especially in patients with advanced disease) likely to be minimal, if they exist at all. In view of the enormous costs and the considerable side-effects, controlled studies preferably using different doses of interferon- $\gamma_{1 \mathrm{~b}}$ are urgently needed to define a role for interferon- $\gamma_{1 b}$ in the treatment of idiopathic pulmonary fibrosis.

Acknowledgements. The authors wish to thank M. Augst from Boehringer Ingelheim, Biberach an der Riss, Germany, for his support.

\section{References}

1. Katzenstein AL, Myers JL. Idiopathic pulmonary fibrosis: clinical relevance of pathologic classification. Am J Respir Crit Care Med 1998; 157: 1301-1315.

2. Daniil ZD, Gilchrist FC, Nicholson AG, et al. A histologic pattern of nonspecific interstitial pneumonia is associated with a better prognosis than usual interstitial pneumonia in patients with cryptogenic fibrosing alveolitis. Am J Respir Crit Care Med 1999; 160: 899-905.

3. Bjoraker JA, Ryu JH, Edwin MK, et al. Prognostic significance of histopathologic subsets in idiopathic pulmonary fibrosis. Am J Respir Crit Care Med 1998; 157: 199-203.

4. American Thoracic Society. Idiopathic pulmonary fibrosis: diagnosis and treatment. International consensus statement. American Thoracic Society (ATS) and the European Respiratory Society (ERS). Am J Respir Crit Care Med 2000; 161: 646-664.

5. Ziesche R, Hofbauer E, Wittmann K, Petkov V, Block LH. A preliminary study of long-term treatment with interferon gamma-1b and low-dose prednisolone in patients with idiopathic pulmonary fibrosis. $N$ Engl J Med 1999; 341: 1264-1269.

6. Raghu G, Colby TV, du Bois RM. Interferon gamma-1b in idiopathic pulmonary fibrosis: reanalysis of a published study. In: King TJ, ed. New Approaches to Managing Idiopathic Pulmonary Fibrosis. New York, American Thoracic Society, 2000; pp. 44-51.

7. Eickelberg O, Pansky A, Koehler E, et al. Molecular mechanisms of TGF-(beta) antagonism by interferon (gamma) and cyclosporine A in lung fibroblasts. FASEB J 2001; 15: 797806.

8. Giri SN, Hyde DM, Marafino BJ Jr. Ameliorating effect of murine interferon gamma on bleomycin-induced lung collagen fibrosis in mice. Biochem Med Metab Biol 1986; 36: 194-197.

9. Elias JA, Freundlich B, Kern JA, Rosenbloom J. Cytokine networks in the regulation of inflammation and fibrosis in the lung. Chest 1990; 97: 1439-1445.

10. Romagnani S. The Th1/Th2 paradigm. Immunol Today 1997; 18: 263-266.

11. Johkoh T, Muller NL, Cartier Y, et al. Idiopathic interstitial pneumonias: diagnostic accuracy of thin-section CT in 129 patients. Radiology 1999; 211: 555-560.

12. Kalra S, Utz JP, Ryu JH. Interferon-gamma $1 \mathrm{~b}$ in the treatment of advanced idiopathic pulmonary fibrosis. Chest 2001; 120: A145.

13. Raghu G, Spada C, Otaki Y, Hayes J. Interferon gamma (IFN-g) in the treatment of advanced idioapthic pulmonary fibrosis (IPF) and fibrotic nonspecific interstitial pneumonia (NSIP-F): prospective, preliminary clinical observations in one center. Chest 2001; 120: A146.

14. Raanani P, Ben-Bassat I. Immune-mediated complications during interferon therapy in hematological patients. Acta Haematol 2002; 107: 133-144.

15. Machold KP, Smolen JS. Interferon-gamma induced exacerbation of systemic lupus erythematosus. J Rheumatol 1990; 17: 831-832.

16. Graninger WB, Hassfeld W, Pesau BB, Machold KP, Zielinski CC, Smolen JS. Induction of systemic lupus erythematosus by interferon-gamma in a patient with rheumatoid arthritis. J Rheumatol 1991; 18: 1621-1622.

17. Friess GG, Brown TD, Wrenn RC. Cardiovascular rhythm effects of gamma recombinant DNA interferon. Invest New Drugs 1989; 7: 275-280.

18. Bouros D, Wells AU, Nicholson AG, et al. Histopathologic subsets of fibrosing alveolitis in patients with systemic sclerosis and their relationship to outcome. Am J Respir Crit Care Med 2002; 165: 1581-1586.

19. Hein R, Behr J, Hundgen M, et al. Treatment of systemic sclerosis with gamma-interferon. Br J Dermatol 1992; 126: 496-501.

20. Kahan A, Amor B, Menkes CJ, Straugh G. Recombinant interferon- $\gamma$ in the treatment of systemic sclerosis. Am J Med 1989; 87: 273-277.

21. Freundlich B, Jimenez SA, Steen VD, Medsger TA Jr, Szkolnicki M, Jaffe HS. Treatment of systemic sclerosis with recombinant interferon- $\gamma$. Arthritis Rheum 1992; 35: 1134 1142.

22. Hunzelmann N, Anders S, Fierlbeck G, et al. Systemic scleroderma. Multicenter trial of 1 year of treatment with recombinant interferon gamma. Arch Dermatol 1997; 133: 609-613.

23. Varga J. Recombinant cytokine treatment for scleroderma. Arch Dermatol 1997; 133: 637-642. 